\title{
Effect of Group Counseling on Attitude About "Child as a Pillar of Life" in Women Referring to Hamadan City Comprehensive Health Centers
}

\author{
Batul Khodakarami ${ }^{1}$, Masumeh Naseritazehgeshlag ${ }^{2}$, Paresa Parsa $^{3 *}$, Unes Mohammadi ${ }^{4}$
}

1. Instructor, Department of Midwifery, Faculty of Nursing and Midwifery, Hamadan University of Medical Sciences, Hamadan, Iran

2. Student, Department of Midwifery, Faculty of Nursing and Midwifery Hamadan University of Medical Sciences, Hamadan, Iran

3. Associate Professor, Department of Mother and Child Health, Faculty of Nursing and Midwifery Hamadan University of Medical Sciences, Hamadan, Iran

4. Assosiate Professor, Depatment of Epidemiology, Public Health Scool, Hamadan University of Medical Sciences, Hamadan, Iran

Article Info

Received: 2018/05/12;

Accepted: 2019/08/06;

Published Online: 2020/04/07

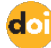

10.30699/ajnmc.28.1.27

Original Article

Use your device to scan and read the article online

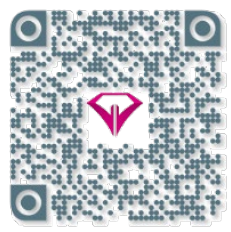

\section{ABSTRACT}

Introduction: Considering the fundamental changes in women's attitudes, especially in Iran, to reduce fertility, the role of family planning programs, various social, cultural, traditional developments and changes related to behaviors and tendencies in reducing fertility, this tried to investigate the impact of group counseling on attitudes about "A child as a pillar of life "in women's attitude referring to comprehensive health centers in Hamadan.

Methods: In this cross-sectional study, 116 eligible women from random health care centers in Hamadan were randomly selected. Data were collected using a demographic information questionnaire and a fertility and childbearing attitude questionnaire. To analyze the data, SPSS 24 was used and 95\% confidence level was considered.

Results: The average age of women was $25.4 \pm 4.4$ years and the mean time of marriage was $3.37 \pm 3.02$ years. $46.20 \%$ of women had a university education and $71.50 \%$ of women had an average household income. In the intervention group, group counseling has been effective in changing women's attitudes toward "children as a pillar of life" $(P<0.01)$.

Conclusion: Women's attitudes toward "children as a pillar of life" have become positive after counseling. It is recommended to hold counseling sessions about the position of the child in life in different age groups, educational levels and at all levels of society.

Keywords: Group counseling, Fertility attitude, Childbearing

Copyright $($ 2020, This is an original open-access article distributed under the terms of the Creative Commons Attribution-noncommercial 4.0 International License which permits copy and redistribution of the material just in noncommercial usages with proper citation.

\section{How to Cite This Article:}

Khodakarami B, naseritazehgeshlag M, parsa $\mathrm{P}$, mohammadi U. Effect of group counseling on attitude about "child as a pillar of life" in women referring to Hamadancity comprehensive health centers. Avicenna J Nurs Midwifery care. 2020; 28 (1) :27-35 


\section{تأثير مشاورة گَروهى بر نكرش به افرزند بهعنوان ركن زندگى" در زنان مراجعه كننده به مراكز جامع سلامت شهر همدان}

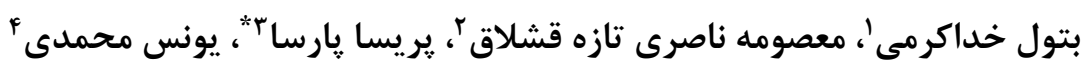

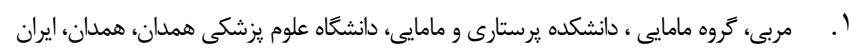

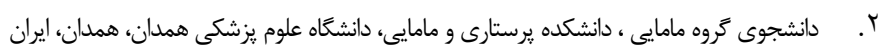

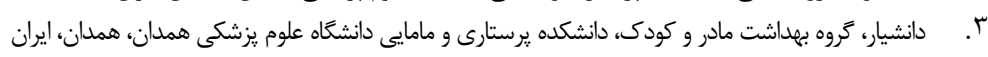

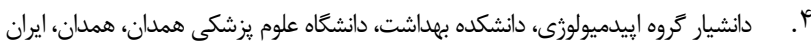

\begin{tabular}{|c|c|}
\hline جكيده & اطلاعات مقاله \\
\hline 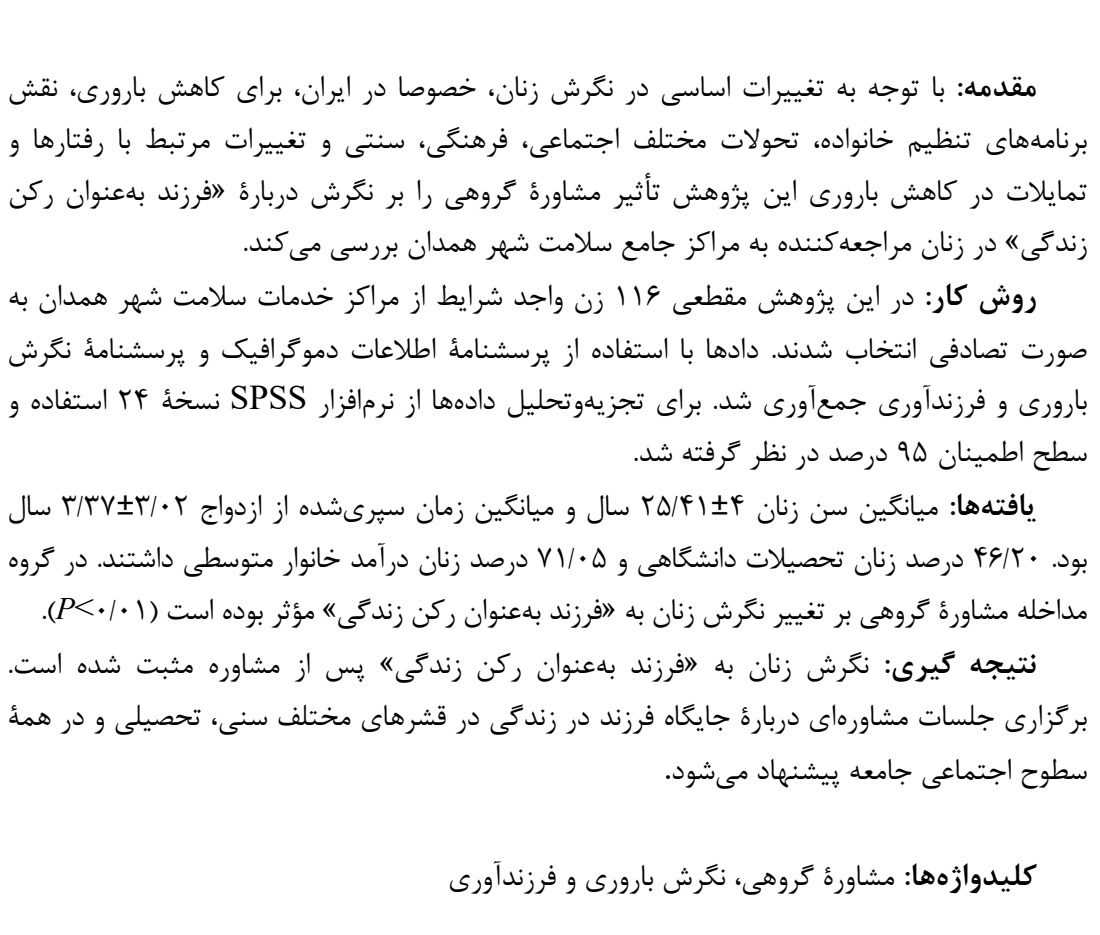 & 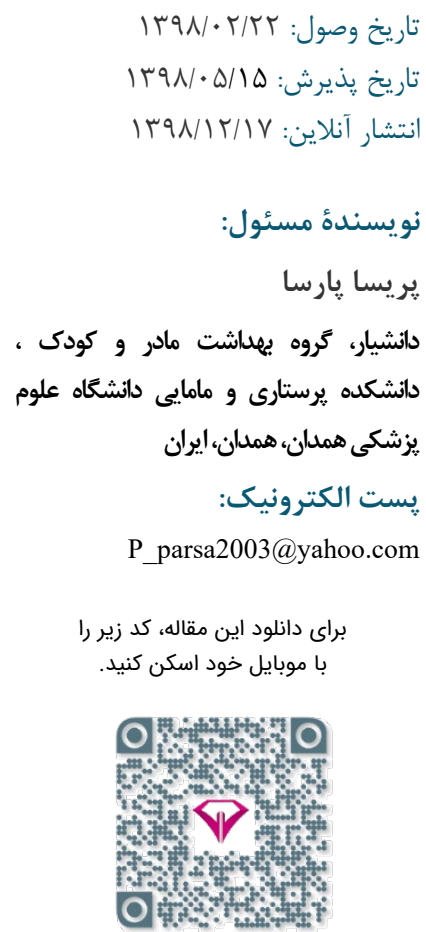 \\
\hline
\end{tabular}

مقدمه

بارورى كاهش يافته است [ع]. نخرش بارورى زنان آمادگى

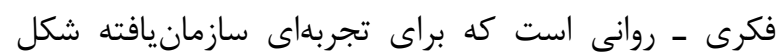

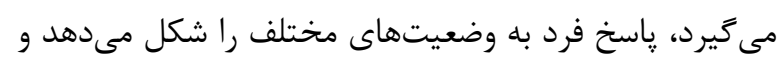

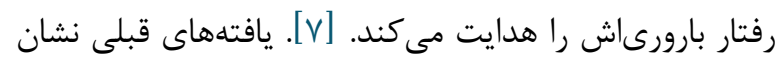

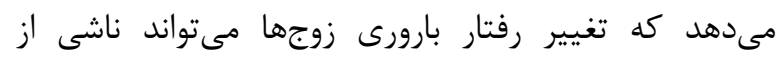

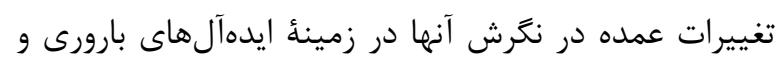

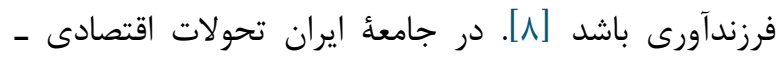

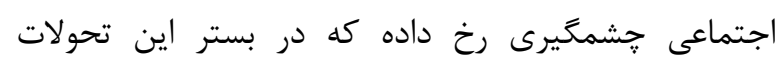

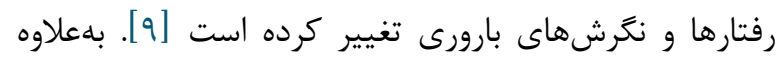

داشتن فرزند از اهداف مهم ازدواج و زندكى مشترى

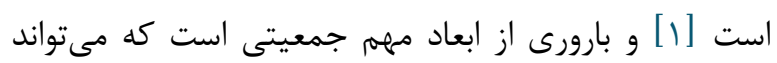

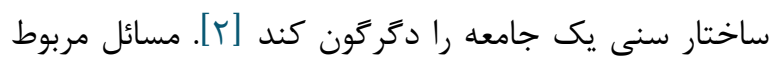

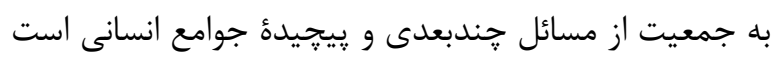

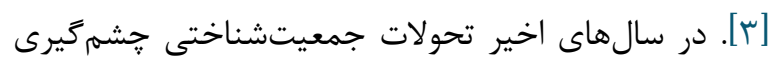

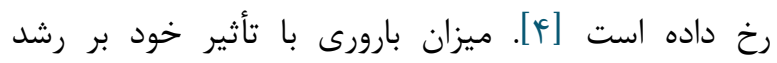

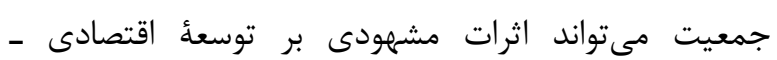

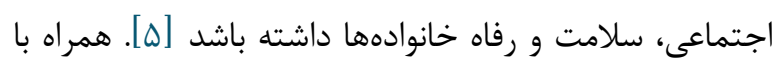

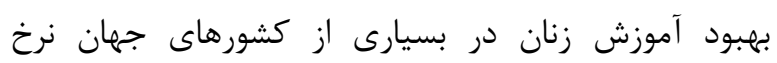


و مالى داشتن فرزند در قبال منافع مختلفى است كه با آنا

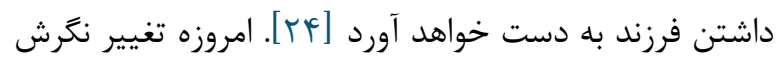

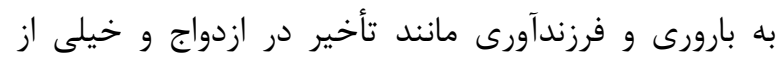

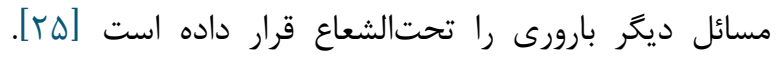

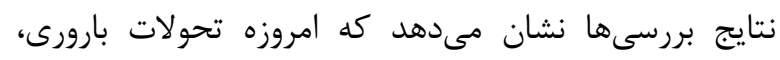

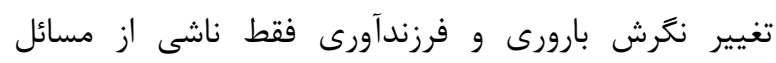

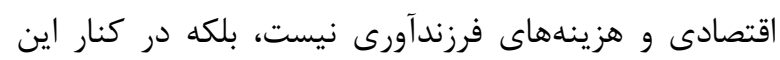

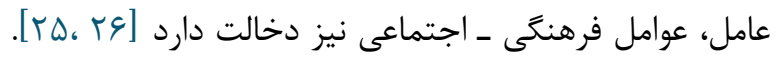

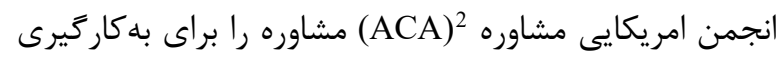

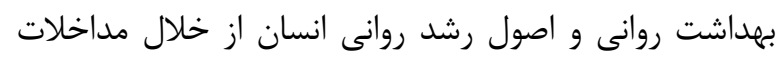

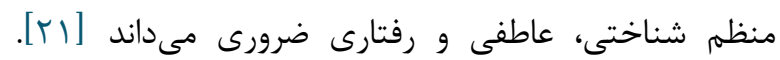

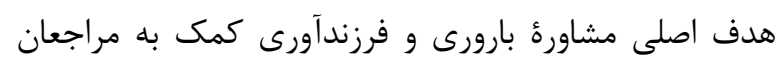

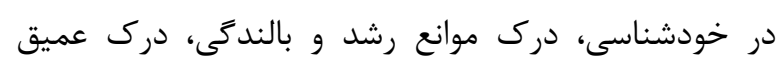

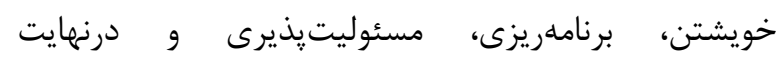

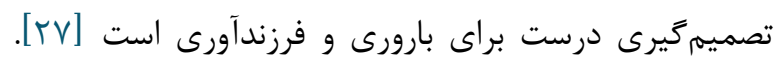

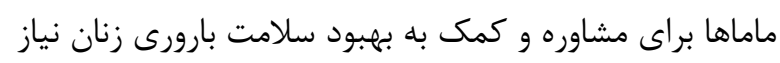

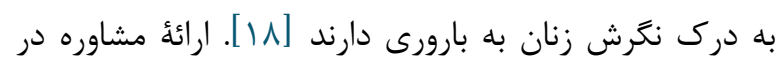

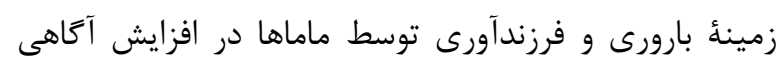

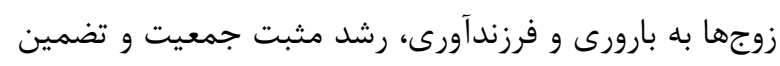

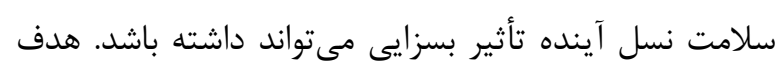

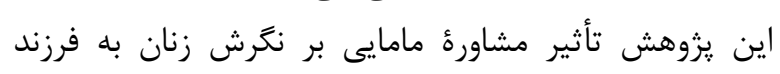

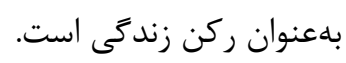

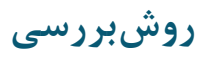

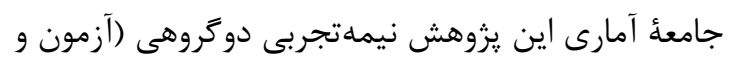

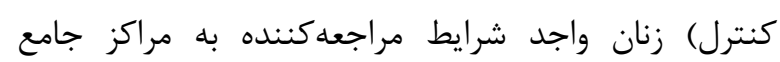

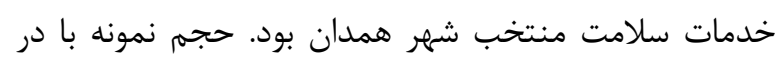

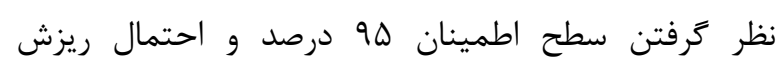

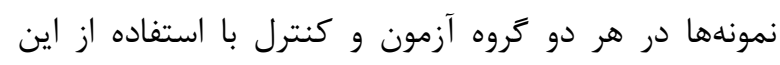

$n=\frac{\left(Z_{1-\frac{\alpha}{2}}+Z_{1-\beta}\right)^{2}\left(\sigma_{1}^{2}+\sigma_{2}^{2}\right)}{d^{2}}$

فرمول زير محاسبه شد:

بر اساس اين فرمول حجم نمونه 119 نفر بود كه به

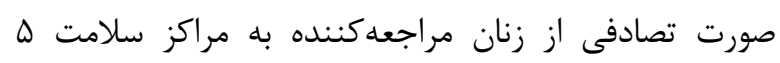

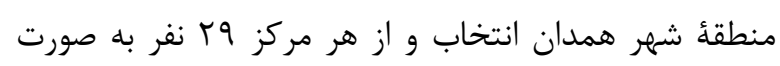

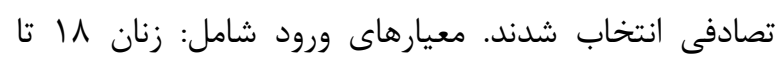

${ }^{2}$ American Conseling Association

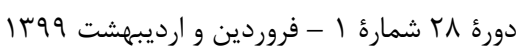

رواج سبكهاى زندگى متفاوت در افراد كرايش آنها را به إداه

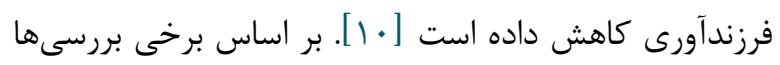

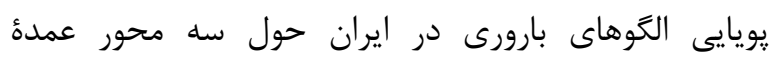

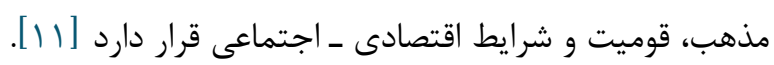

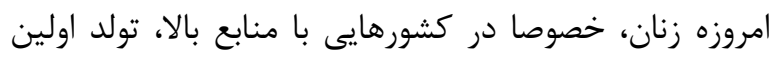

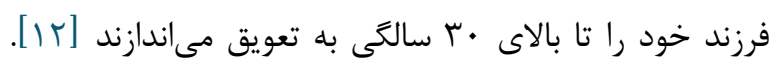
در بررسىهاى سلامت همعانى و جمعيتى فاصلئ ازدواج زنان اندان

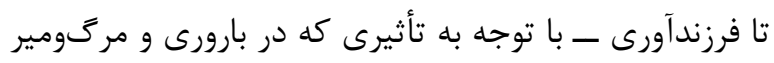

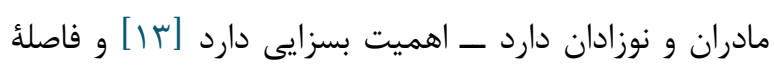

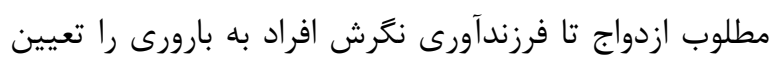

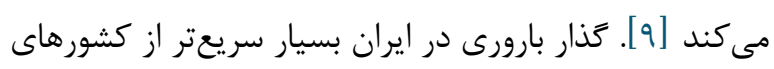

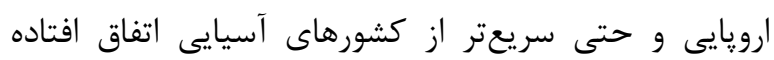

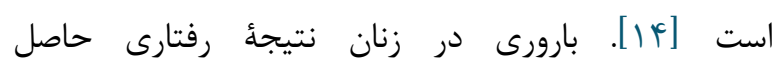
تصميمكيرى در خارجوب خانواده است. زن و و مرد عوامل

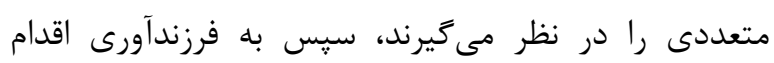

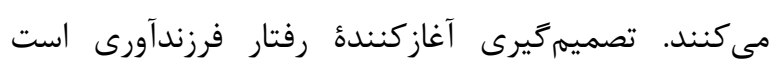

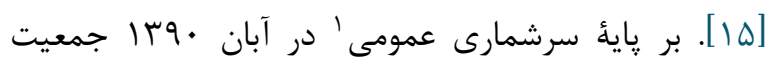

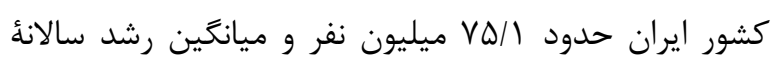

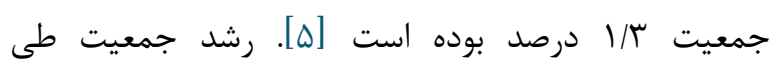

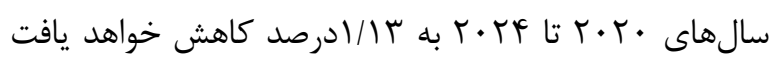

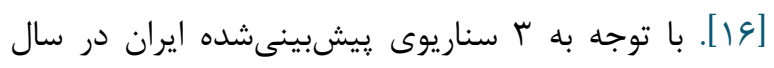

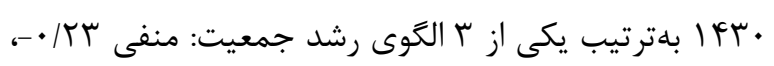

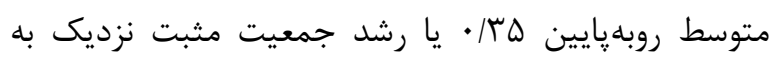

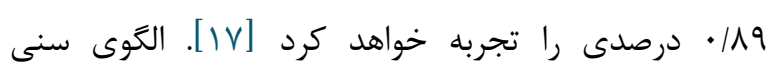

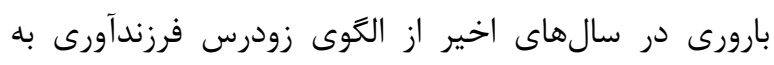

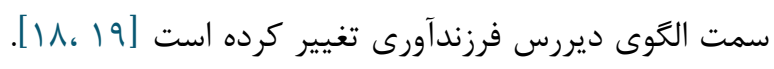

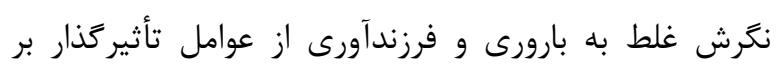

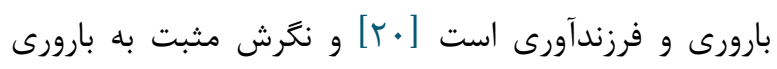

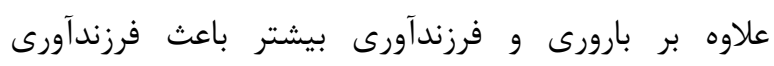

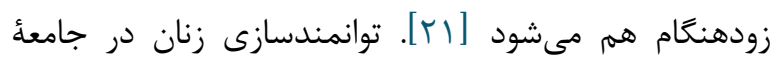

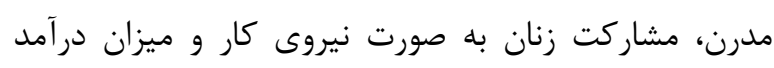

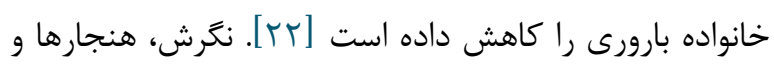

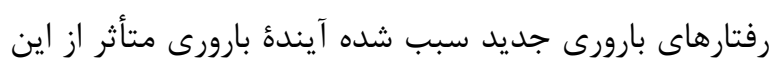

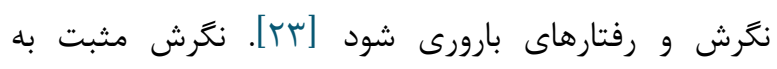

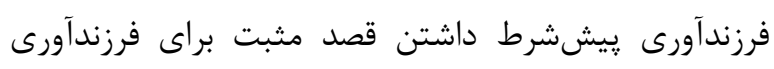

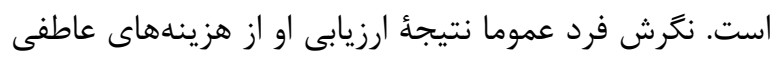

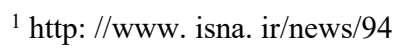


و فرزندآورى بr سؤال و \& زيرمقياس دارد كه زيرمقياسها به صورت ليكرت لددرجهاى كاملا موافقم (ه)، موافقم (Y)،

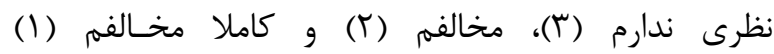

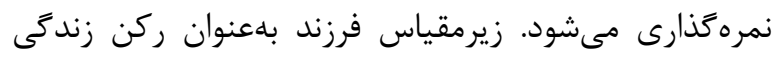

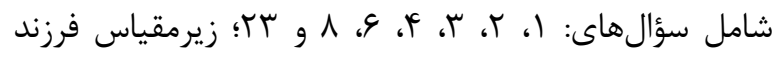

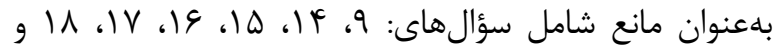

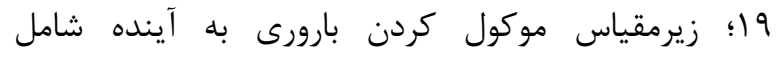

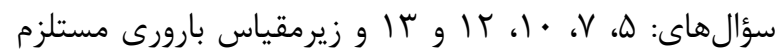

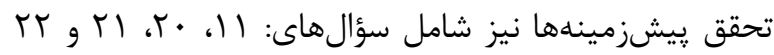

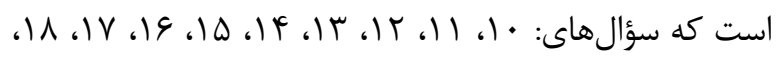

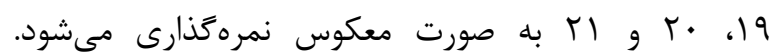

هأساله است كه بيش از يكسال از ازدواج آنها مى كذرد، فرزند ندارند، نازا نيستند، سلامت جسمى - روانى و حداقل

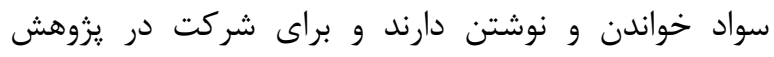

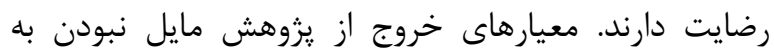

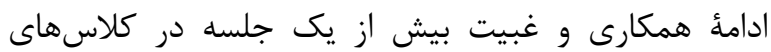

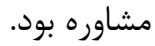

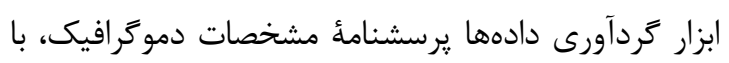

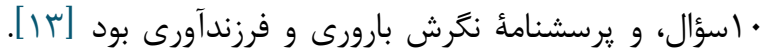

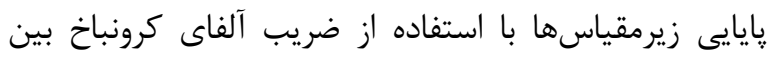

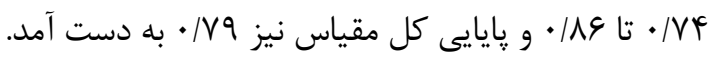

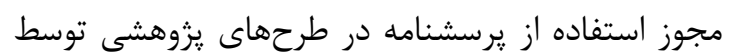

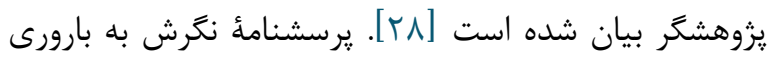

جدول ا. محتواى جلسات مشاوره

\begin{tabular}{|c|c|}
\hline محتوا & تعداد جلسه \\
\hline سلام وخوشامدگويى، برقرارى رابطؤ كلامى، كرفتن اطلاعات در خصوص نكرش زنان به بارورى براى هر دو گروه (تكميل & جلسهُ اول \\
\hline 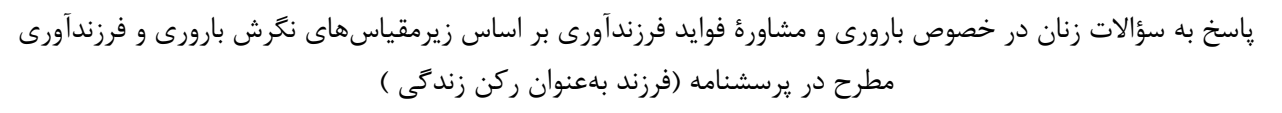 & جلسئ دوم \\
\hline 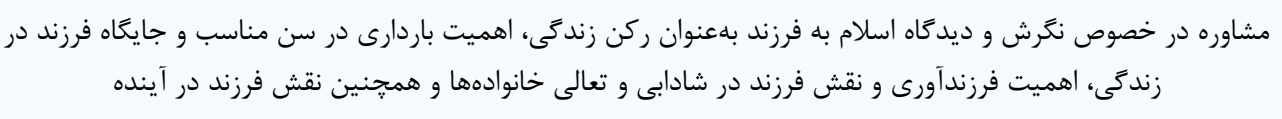 & جلسةٔ سوم \\
\hline مرور كلى سه جلسهٔ قبل و ارائٔ اطلاعات تكميلى و توضيح درخصوص زمان مراجعه براى تشكيل يرونده يِيش از باردارى & جلسئ جههارم \\
\hline
\end{tabular}

يس از دريافت كد اخلاق و معرفىنامة يزوهش از دانشخاه

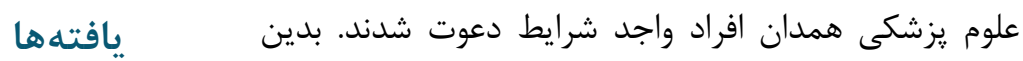
در اين يزوهش 11 الم نفر از زنان واجد شرايط مراجعهكننده به مراكز جامع خدمات سلامت شهر همدان شركت كردهاند. در

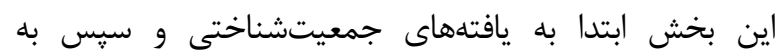
يافتههاى استنباطى مى يردازيم.

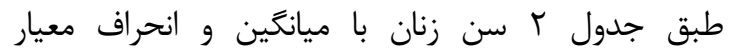

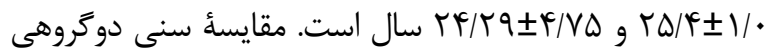
نشان مىدهد كه از نظر آمارى گروه كنترل و مداخله تفاوت

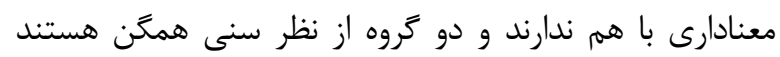
(P=•/IV) معيار F/T/Y منظور يرسشنامهها يس از دادن توضيحات كافى در مورد اهداف يزوهش و نحوه تكميل آن در اختيار شركت كنند

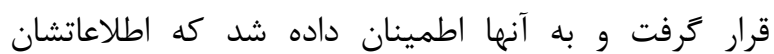
محرمانه مىماند. يس از † جلسه مشاوره و تكميل يرسشنامه

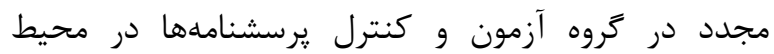
SPSS Inc., Chicago, Ill. ) نسخهُ SPSS نرمافزار آمارى (USA

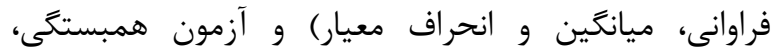
تجزيهوتحليل شد. علاوه بر اين سطح آمارى معنادار و مقدار ه • • • P-value 
צ F/• درصد شركت كنند در گروه مداخله تحصيلات دانشكاهى (فوق دييلم ،ليسانس و د دئن

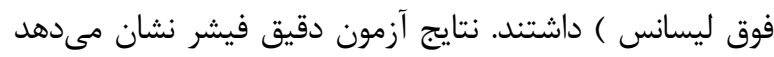

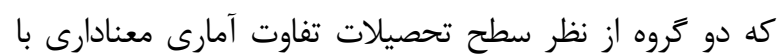
هم ندارند و همكن هستند (

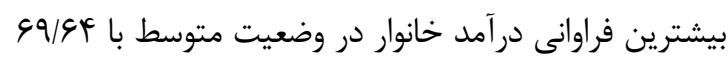

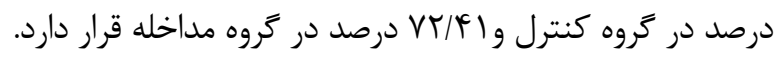

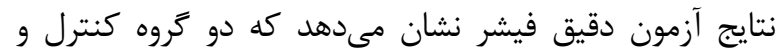

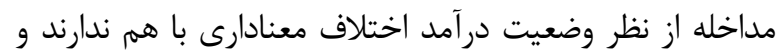

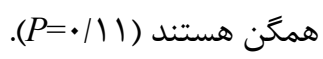

ازدواج دوكروهى نشان مىدهد كه از نظر آمارى كروه كنترل و مداخله تفاوت معنادارى باهم ندارند و دو گَروه با هم همكن

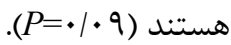

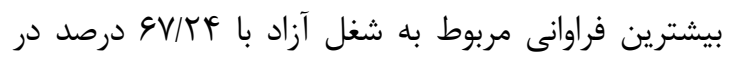
كروه كنترل و FN/TN

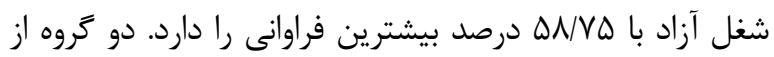

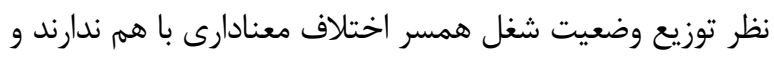

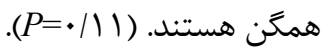

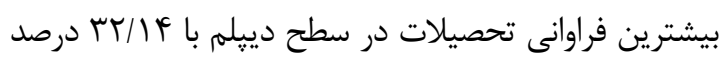
در تروه كنترل و آ/عب درصد در كروه مداخله قرار دارد.

جدول r. توزيع فراوانى سن افراد در دو گروه كنترل و مداخله

\begin{tabular}{|c|c|c|c|c|c|c|}
\hline \multirow{2}{*}{ p-value } & \multicolumn{2}{|c|}{ Fروه مداخله } & \multicolumn{2}{|c|}{ تروه كنترل } & \multirow[t]{2}{*}{ تروه ها } & \multirow[b]{2}{*}{ متغير ها } \\
\hline & انحراف معيار & ميانگين & انحراف معيار & ميانگين & & \\
\hline$\cdot / 1 \mathrm{~V}$ & $\boldsymbol{F} / \cdot$ & $r \Delta / T^{c} I$ & $F / V D$ & $r F / r q$ & \multicolumn{2}{|c|}{ سن } \\
\hline .1 .9 & $r / \cdot r$ & $f|/| f$ & $I T / T F$ & rI/l & \multicolumn{2}{|c|}{ مدت زمان ازدواج } \\
\hline \multirow{6}{*}{$V / D$} & درصد & تعداد & درصد & تعداد & \multirow{2}{*}{ كارمند } & \multirow{6}{*}{ شغل همسر } \\
\hline & $r$ r & rT & $r \cdot / V$ & IT & & \\
\hline & $F \wedge / T \wedge$ & rᄉ & $G V / T F$ & ץq & شغل آزاد & \\
\hline & $\mid r / \cdot V$ & V & $V / I F$ & f & بيكار & \\
\hline & . & - & I/VT & 1 & بازنشسته & \\
\hline & I/VT & 1 & . & . & خانهدار & \\
\hline \multirow{5}{*}{$1 / \Delta F$} & $r F / I F$ & 14 & $I V / 9 \wedge$ & $1 \cdot$ & زير دييلهم & \multirow{5}{*}{ تحصيلات } \\
\hline & TG/TI & rI & $r r / l f$ & 11 & دييلم & \\
\hline & $1 r / v q$ & $\Lambda$ & 191.9 & 9 & فوقدييلم & \\
\hline & $r F / I F$ & If & & IV & ليسانس & \\
\hline & I/TV & 1 & $r / \Delta V$ & $r$ & بالاتر & \\
\hline \multirow{3}{*}{.$/ 94$} & $r F / I F$ & $1 f$ & re/Vq & 10 & كم & \multirow{3}{*}{ خانوار } \\
\hline & $V Y / Y^{c}$ & Fr & q9/9४ & rq & متوسط & \\
\hline & $\Gamma / \mathcal{C} \Delta$ & $r$ & $r / \Delta V$ & $r$ & بالا & \\
\hline
\end{tabular}




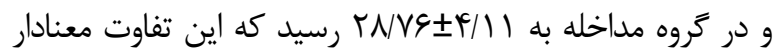
است (1 • / > (P). مقايسٔ گروه كنترل و مداخله نشان مى مدهد كه نخرش زنان در گروه مداخله بعد از مشاوره به زيرمقياس فرزند بلعنوان ركن زندگى بهبود يافته است.
جدول ب نشان مىدهد ميانگين و انحراف معيار زيرمقياس

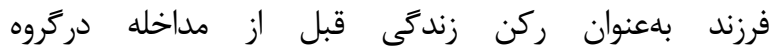
كنترل • / / گروه اختلاف معنادارى با هم ندارند و همگن هستند. پس از

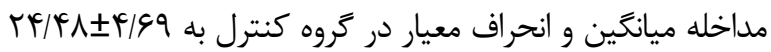

جدول r. مقايسهُ زير مقياس فرزند بهعنوان ركن زندكى افراد در دو كروه كنترل و مداخله

\begin{tabular}{|c|c|c|c|c|c|c|c|c|c|}
\hline \multirow{2}{*}{ P-value } & \multirow{2}{*}{$\mathrm{df}$} & \multirow{2}{*}{$\mathrm{t}$} & \multicolumn{3}{|c|}{ بعد از مداخله } & \multicolumn{3}{|c|}{ قبل از مداخله } & \multirow{2}{*}{ كروه } \\
\hline & & & انحراف معيار & ميانگين & تعداد & انحراف معيار & ميانگين & تعداد & \\
\hline$\cdot / 79$ & $\Delta \Delta$ & $1 / \cdot V$ & $1 / 99$ & $r F / F \Lambda$ & $\Delta \varphi$ & $\Delta / 1$. & TY/AT & $\Delta \varphi$ & كنترل \\
\hline$<\cdot 1 \cdot 1$ & $\Delta V$ & $-9 / \Delta \Delta$ & $4 / 11$ & TNVE & $\Delta \Lambda$ & $\Delta / \Delta F$ & TF/GG & $\Delta \Lambda$ & مداخله \\
\hline
\end{tabular}

بارورى و فرزندآورى است [1/]]. نتايج يزوهش Piltan و Rahmanian اهميت داشتن فرزند بر كاهش هزينههاى فرزنديرورى، فراهم

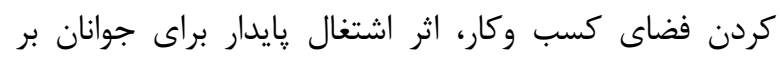

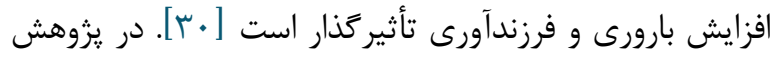
Adair

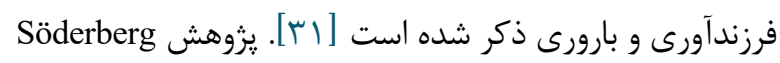

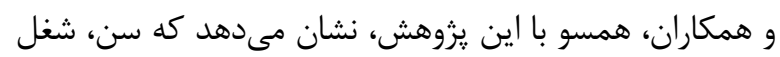
و منطقة سكونت زنان نقش مهرمى در نخرش آنها به بارورى و

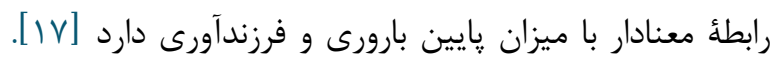
اين يزوهش نشان مىدهد كه اكثر زنان تمايل به تأخير

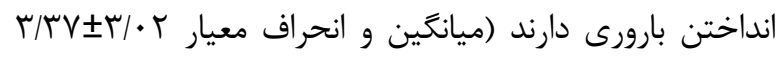
سال) كه با يزوهشهاى قبلى همخوان است. در يزوهش

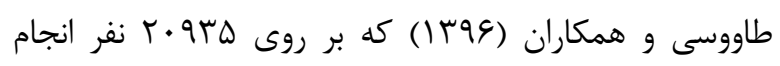
شده بود، بيش از دوسوم زنان ازدواج كرده تمايل به كاهش ونمان

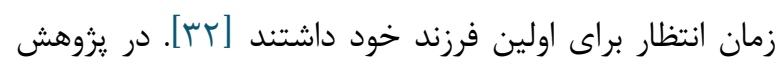
Dekker جمعى معنادار و معكوس به دست آمد، يعنى وسايل ارتباطى و

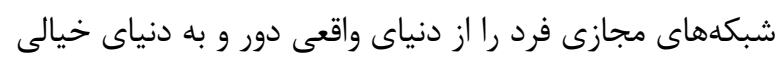
وارد مى كنند. در نتيجه باعث فردگرايى و كاهش بارى بارورى مىشوند [ • [r]. در اين يزوهش نتايج مربوط به سطح سواد

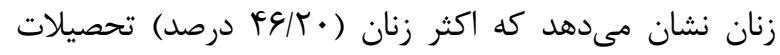
دانشگاهى دارند و افزايش سطح سواد زنان بر نترش بارورى
در سالهاى كذشته جهان شاهد كاهش بارورى بوده و اين روند در ايران كاهش شخفتانخيزى داشته است. اين يزوهش

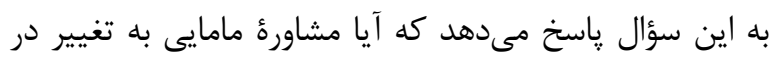

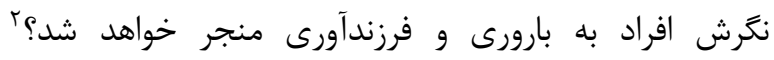

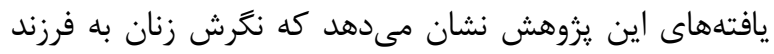

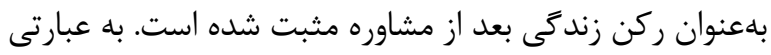

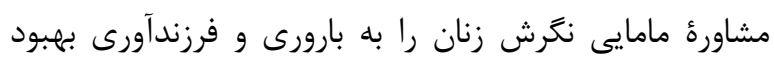
داده است. در يزوهش Söderberg و همكاران در سوئد نشان مى دهد كه زنان شهرنشين با وضعيت اقتصادى ـ اجتماعى بالا

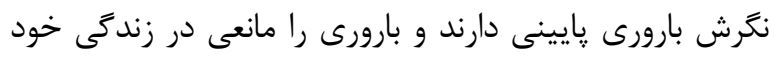
تلقى مى كنند، ولى مادر شدن را بهعنوان هويت زن بـن بودن مهرئم

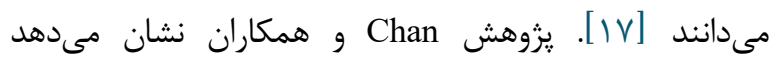

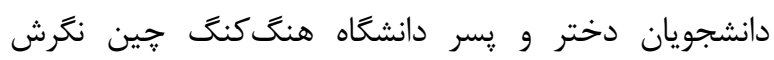
بارورى پايينى دارند كه مهرمترين علل آن نخرانى در مورد شرايط اقتصادى، آينده شغلى، مشكل مالى، فقدان آمادكى و

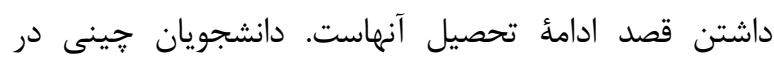
مقايسه با دانشجويان غربى احساس عاطفى بالاتر و نخرش يايينترى به بارورى دارند [ع].

خوشبختى خانواده در زرو وجود بجهه است و آن را يكى از باز

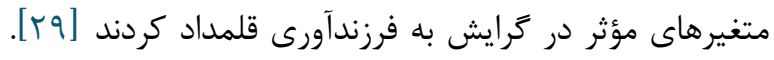

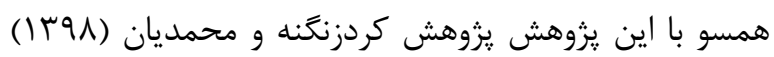

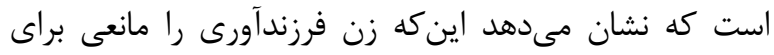
زندكى شخصى و اجتماعى ببيند يا نه، يكى از اركان نخرش 
نتايج اين يزوهش نشان مىدهد كه نكرش زنان بِ از

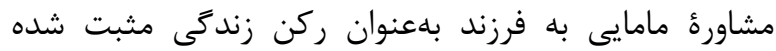

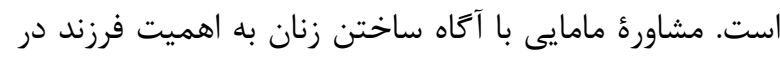
زندگى - با توجه به يِير شدن جمعيت و نياز افراد مخصوصا

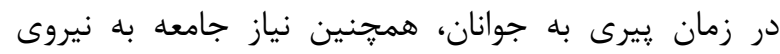

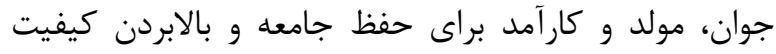

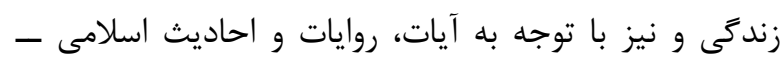

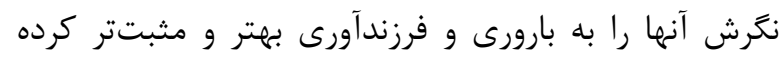
است.

با توجه به مشكلات و موانع موجود در جامعه و مشكلات

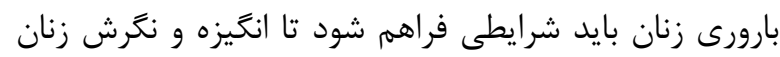

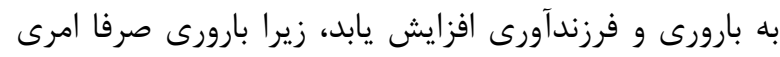

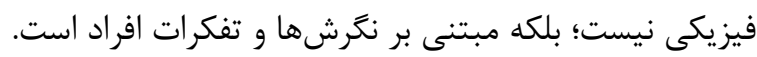

\section{سياسگزارى}

از استاد كرامى ام سركار خانم بطول خداكرمى بسيار

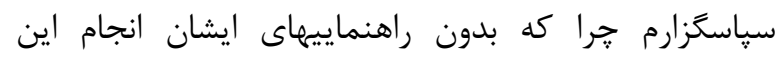

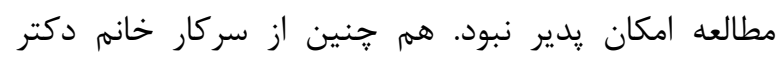

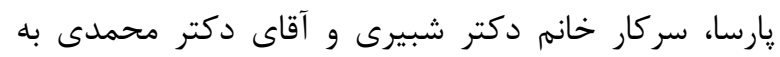

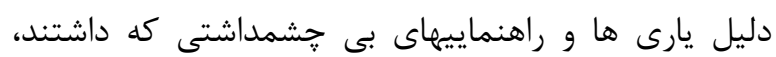
نهايت تشكر را دارم. - ماري

$$
\text { تعارض در منافع }
$$

بين نويسندًان هيجَّونه تعارضى در منافع وجود ندارد

$$
\text { منابع مالى }
$$

منابع مالى اين مطالعه توسط نويسندكان تامين شده است.

\section{References}

1. Rad F, Savabi H. Investigation on Tendency to Fertility and Its Related Social Factors (a Case Study of Married Women aged 15 to 50 in Tabriz). Journals Managment System. 2015;3(1): 127-55.

2. Hadi SD. Determinants of Demographic, Social, Cultural and Economic Conditions Affecting Fertility: The Case Study of Married Women in Oshnavieh City. Tehran: kharazmi University; 2013.
آنها تأثيركذار است. بر اساس مستندات علمى پيشين نيز تحصيلات عامل مهمى در نخرش بارورى خانوادههاست و

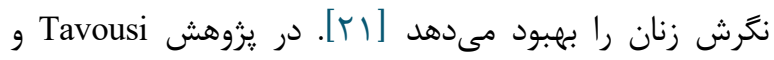

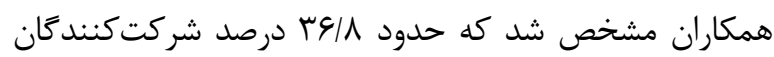
به فرزندآورى تمايل دارند [سب]. نتايج يزوهش Krisher و همكاران (Y) (Y) نشان مى دهد

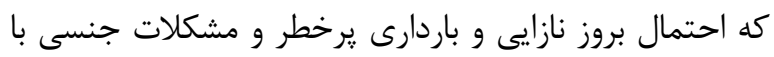

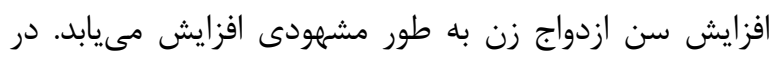

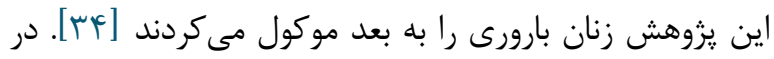

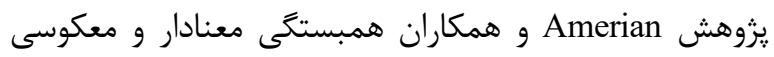

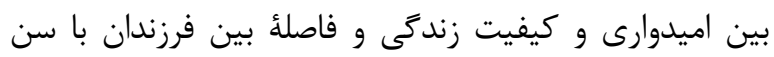
تصميمَيرى براى اولين فرزندآورى وجود دارد [هـr].

\section{نتيجه كيرى}

جامعأ ايران تحت تأثير مدرنيته است. اين مدرنيته بر

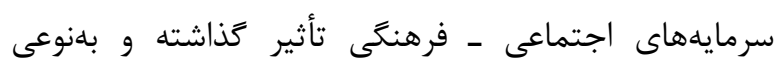

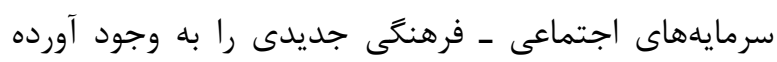

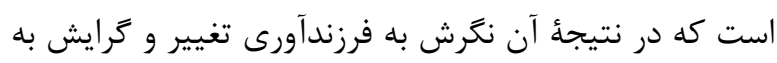

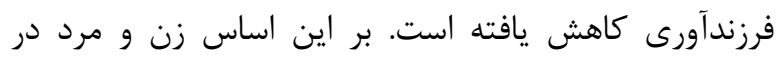

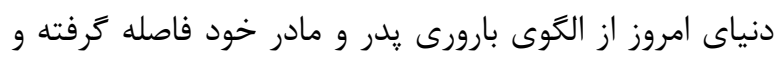

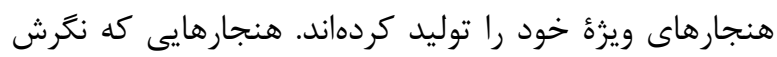

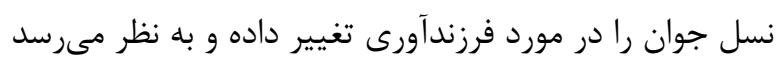

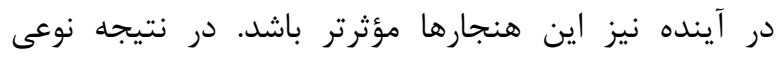

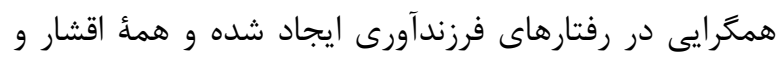

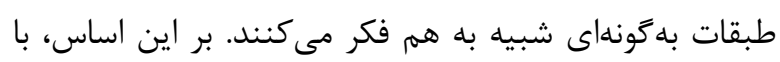

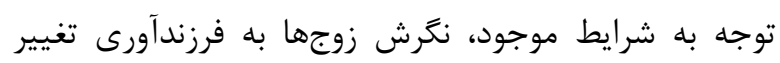
اساسى كرده است.

3. Delavari A, Mahdavihezave A, Nouroozinejad A, Yarahmadi SH. National Diabetes Control and Prevention Program. Tehran: Sound Publishing Center. 2014.

4. Mobasheri M, Alidosti M, Heidari Soureshjani S, Khosravi F, Khalafeyan P, Jalilian M. Determination of the Most Important Factors Influencing the Fertility Patterns of Single Child and Without Child Families in Shahr-e-kord city in 2013. scientific journal of ilam university of medical sciences. 2013;21(6): 63-70.

$$
\text { مجله مراقبت يرستارى و مامايى ابنسينا }
$$




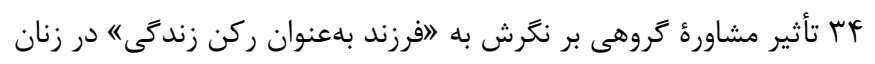

5. Ramezankhani A, Manouchehri H, Hajizadeh E, Haghi M. The Decision-Making Process of Childbearing: a Qualitative Study. Payesh (Health Monitor). 2013 Oct 15;12(5):505-15.

6. Chan $\mathrm{CH}$, Chan TH, Peterson BD, Lampic C, Tam MY. Intentions and Attitudes Towards Parenthood and Fertility Awareness Among Chinese University Students in Hong Kong: a Comparison with Western Samples. Human Reproduction. 2015 Feb 1;30(2):364-72.

7. Jalovaara M, Neyer G, Andersson G, Dahlberg J, Dommermuth L, Fallesen P, Lappegård T. Education, gender, and cohort fertility in the Nordic countries. European Journal of Population. 2019 Jul 15;35(3):563-86.

8. Childbearing Among Married Women in Tehran City.2016:2(14): 217-34.

9. Ju K, Kopp M, Wang Y, Yuan G, Zheng W, Ataman LM, Woodruff TK, Chen Q, Xiao S. A Survey Study of Attitude and Knowledge Regarding Female Fertility Preservation Among Reproductive Health Professionals in Fujian, China. Journal of adolescent and young adult oncology. 2019 Feb 1;8(1):67-73.

10. Saadati M, Bagheri A. Ideal First Birth Interval: A Study of Pre-Marriage Youths. Payesh (Health Monitor). 2017 Apr 15;16(2):239-50.

11. Kavehfirooz Z, Zare B, Jahanbakhsh GS. The Effect of Socio-Cultural Capitals on Attitudes Towards Childbearing (Case Study: Tehranian Couples Going to Marry). 2017

12. Taghizadeh Z, Behmanesh F, Ebadi A. Marriage Patterns and Childbearing: Results from a Quantitative Study in North of Iran. Global journal of health science. 2016 Mar;8(3):1.

13. Colleran H. The Cultural Evolution of Fertility Decline. Philosophical Transactions of the Royal Society B: Biological Sciences. 2016 Apr 19;371(1692):20150152.

14. Baezzat F, Marzbani Y, Ahmadi Ghozlojeg A, Karimi A, Azarnioshan B. A Study of Psychometric Properties of Persian Version of Attitudes Toward Fertility and Childbearing Scale. The J Urmia Nurs Midwifery Fac. 2017;15(1):37-47.

15. Hosseini G, Hosseini H. Comparing Determinants of Fertility Behaviour Among Kurdish Women Living in Rural Areas of Ravansar and Gilangharb Cities. J Kermanshah Univ Med Sci. 2013;17(5):316-24.

16. Kariman N, Simbar M, Ahmadi F, Vedadhir AA. Socioeconomic and Emotional Predictors of Decision Making for Timing Motherhood Among Iranian Women in 2013. Iranian Red Crescent Medical Journal. 2014 Feb;16(2).

17. Lund EM. Be Ye Fruitful and Multiply: Does Religious Activation Increase Reproductive Desire? 2014.
18. Hosseini H, Bagi B. Socioeconomic, Cultural and Demographic Determinants of Childbearing Desires Among Married Women Attending Health Centers in Hamedan (2012). J Kermanshah Univ Med Sci. 2014;18(1):35-43.

19. Söderberg M, Lundgren I, Christensson K, Hildingsson I. Attitudes Toward Fertility and Childbearing Scale: An Assessment of a New Instrument for Women Who Are Not Yet Mothers in Sweden. BMC pregnancy and childbirth. 2013 Dec;13(1):197.

20. Seymour JW, Frasso R, Shofer FS, Bennett IM. Cohort Study of Early Literacy and Childbearing Over the Reproductive Lifecourse. BMJ open. 2016 Dec 1;6(12):e013522.

21. 20. Dekker RL, King S, Lester K. Social media and evidence-based maternity care: a cross-sectional survey study. The Journal of perinatal education. 2016 Jan 1;25(2):105-15.

22. Kordzanganeh J, Mohamadian H. Psychometric Assessment of the Validity of the Iranian Version of Attitude Toward Fertility and Childbearing Inventory in Women Without a History of Pregnancy in the South of $\begin{array}{lllll}\text { Iran. } \quad \text { sjsph. } \quad 2019 ; & 17 & \text { (1) }\end{array}$ URL: http://sjsph.tums.ac.ir/article-1-5737-fa.html

23. Saei GM, Ozgoli G, Hajizadeh F, Sheikhan Z, Nasiri M, Jannesari S. The Relationship Between Religious Orientation with Intention of Desired Fertility and Actual and Desirable Number of Children in Working Women of Tehran, Iran. Journal of Research on Religion \& Health. 2017;3(1).

24. Keshavarz H, Bahramian M, Mohajerani AA, Hosseinpour K. Factors Effective in Changing of Reproductive Behaviors of Nomadic and Non-Nomadic Tribes in the Semirom Province, Iran 2014.

25. Hosseini. H, Asgare. A, Moradi. N. A Comparative Study of Childbearing Desires of Shia and Sunni Kurdish Women in Rural Areas of Kamyaran. Women and Family Studies. 2016 Mar 20;4(1):63-84.

26. Hosseini H, Asgari-Nadushan A, Moradi N. Comparative study of childbearing desires Shiite and Sunni Kurdish women in rural areas of Kamyaran city. J Woman Fam Stud. 2016;4(1):63-84.

27. Farrokh Eslamlou HR, Mogadam Tabrizi F, Moeini SR, Vahabzadeh Z. Pre-Marriage Couplesfertility Attitude Following Recent Childbearing Persuasive Policies in Iran. The Journal of Urmia Nursing and Midwifery Faculty. 2013;11(10):836-46.

28. Fooladi E, Weller C, Salehi M, Abhari FR, Stern J. Using Reproductive Life Plan-Based Information in a Primary Health Care Center Increased Iranian Women's Knowledge of Fertility, But not Their Future Fertility Plan: A Randomized, Controlled Trial. Midwifery. 2018 Dec 1;67:77-86. 
29. Baezzat F, Marzbani Y, Ahmadi Ghozlojeg A, Karimi A, Azarnioshan B. A Study of Psychometric Properties of Persian Version of Attitudes Toward Fertility and Childbearing Scale. The J Urmia Nurs Midwifery Fac. 2017;15(1):37-47.

30. Enayat H, Parnian L. The Study of Cultural Globalization and Tendency to Fertility. 2013.

31. Piltan F, Rahmanian M. Sociological Study of Factors Affecting Willingness to Childbearing Women and Married Men (Case Study: Women and Men 52 to 52 Years Old in Jahrom). Social Development Studies. 2015;7(2):121-34.

32. Adair LE. Fertility Decision Making: to What Extent Do Adaptations, Social Pressures, and Individual Differences Influence Plans to Have a Child? (Doctoral Dissertation, Kansas State University). 2013

33. Mahmoud Tavousi, Aliasghar Haerimehrizi, Jila Sadighi, Mohammad Esmaeil Motlagh, Mohammad Eslami, Fatemeh Naghizadeh, et al . Fertility desire among Iranians: a nationwide study. Payesh. 2017; 16 (4) $: 401-410$ URL: http://payeshjournal.ir/article-1-89-fa.html

34. Tavousi M, Haerimehrizi A, Sadighi J, Motlagh ME, Eslami M, Naghizadeh F, Anbari M, Hasemi A, Montazeri A. Fertility Desire Among Iranians: a Nationwide Study. Health Monitor Journal of the Iranian Institute for Health Sciences Research. 2017;16(4): 401-10.

35. Krisher RL. Maternal age affects oocyte developmental potential at both ends of the age spectrum. Reproduction, Fertility and Development. 2019 Jan 21;31(1):1-9.

36. Amerian M, Kariman N, Janati P, Salmani F. The Role of Individual Factors in Decision Making for the First Childbearing. Payesh (Health Monitor). 2016 Apr $15 ; 15(2): 143-51$. 